\title{
Evaluation of five treatments to control intestinal parasites in sheep in Ayapango, state of Mexico
}

\author{
Rafael Heredia ${ }^{1}$, Emma Aguilar ${ }^{2}$, Camilo Romero ${ }^{3}$, Linda Bautista ${ }^{3}$ and Germán Mendoza ${ }^{4}$
}

1. Department of Agricultural Sciences and Natural Resources, University Center UAEM Amecameca, Autonomous University of Mexico State, Mexico; 2. Department of Veterinary Medicine, University Center UAEM Amecameca, Autonomous University of Mexico State, Mexico; 3. Department of Veterinary Medicine, Research Academician of Animal Health, University Center UAEM Amecameca, Autonomous University of Mexico State, Mexico; 4. Department of Agricultural and Animal Production, Autonomous Metropolitan University Xochimilco, Mexico City, Mexico.

Corresponding author: Camilo Romero, e-mail: cromeron@uaemex.mx, RH: rafaesbirro@hotmail.com, EA: gaby_am93@hotmail.com, LB: lin_bag@yahoo.com.mx, GM: gmendoza5812@gmail.com

Received: 23-05-2016, Accepted: 03-10-2016, Published online: 12-11-2016

doi: 10.14202/vetworld.2016.1233-1237 How to cite this article: Heredia R, Aguilar E, Romero C, Bautista L, Mendoza G (2016) Evaluation of five treatments to control intestinal parasites in sheep in Ayapango, state of Mexico, Veterinary World, 9(11): 1233-1237.

\begin{abstract}
Aim: Intestinal parasites are one of the most common problems in sheep production systems. However, the strategies used to eliminate these parasites have not yielded satisfactory results. Therefore, the aim of this study was to determine the effect of five anthelmintics (with different active ingredients) on the parasite load in sheep.

Materials and Methods: In this study, 107 Rambouillet breed sheep were randomly assigned to five groups. Next, fecal samples were taken directly from the rectum and sent to the laboratory for analysis. We then dewormed each group of sheep using different anthelmintic products: Ivermectin 1\%/clorsulon 10\%, levamisole $12 \%$, closantel sodium 5\%, ivermectin $10 \%$, and closantel $5 \%$ /albendazole $3.75 \%$ with a dosage corresponding to each sheep. At 15 days post-treatment, we took fecal samples and performed a coproparasitoscopic study, using the Faust flotation technique to assess the presence or absence of parasite eggs and the McMaster technique to quantify eggs.
\end{abstract}

Results: Ivermectin/clorsulon was more effective in eliminating parasites than other anthelmintics used, especially in Haemonchus spp.

Conclusion: The results of this study indicate that using ivermectin/clorsulon decreases the number of eggs in feces and is one alternative in controlling parasites in sheep, leading to a reduction in the incidence of health problems, and consequently, improved productivity.

Keywords: anthelmintics, control, intestinal parasites, sheep.

\section{I ntroduction}

Intestinal parasites such as Haemonchus spp., Moniezia spp., Ostertagia spp., and Chabertia spp. are one of the most common health problems affecting sheep (especially young animals), and which seriously affect their health, causing poor weight gain, thus making them susceptible to secondary diseases that may eventually cause death [1]. Such problems incur significant economic losses for producers. Grazing management is a factor that predisposes sheep to acquire parasites [2]. The use of anthelmintics in cattle has reduced the impacts of gastrointestinal nematodes [3]. Control strategies involve actions directed to the host, to eliminate parasites and thereby reduce the contamination of pastures [4].

Frequent use of broad spectrum anthelmintics has greatly increased the prevalence of anthelmintic

\footnotetext{
Copyright: Heredia, et al. Open Access. This article is distributed under the terms of the Creative Commons Attribution 4.0 International License (http://creativecommons.org/licenses/ by/4.0/), which permits unrestricted use, distribution, and reproduction in any medium, provided you give appropriate credit to the original author(s) and the source, provide a link to the Creative Commons license, and indicate if changes were made. The Creative Commons Public Domain Dedication waiver (http:// creativecommons.org/publicdomain/zero/1.0/) applies to the data made available in this article, unless otherwise stated.
}

resistance [5], which is why we need studies that provide insight into the types of parasites present in sheep to determine the antiparasitic strategy that should be employed.

In Mexico, products derived from benzimidazole and macrocyclic lactones are the most frequently used in cases of intestinal parasites, given their broad spectrum of action. High parasitic resistance to benzimidazole has been observed, but this is not the case with macrocyclic lactones [6]. Ivermectins are semisynthetic macrocyclic lactones derived from avermectin. Using ivermectin in cattle in Mexico depends on the farmer's and/or veterinarian's perception of the likelihood of parasite infestation of the cattle, which tends to be seasonal [7]. The State of Veracruz, as one of the main cattle producers in the country, consumes large amounts of ivermectin, which could also be the case in other states of México [8]. The constant use of levamisole has led to reduced efficiency $(30 \%)$ in the control of gastrointestinal nematodes (Haemonchus contortus and Cooperia curticei) in hair sheep. Moreover, the combination of levamisole with ivermectin is associated with anthelmintic resistance, and closantel/albendazole also leads to resistance, tested using the larval motility test 
in vitro in a study conducted in the state of Chiapas in Mexico [9]. Albendazole, a benzimidazole derivative, is an anthelmintic drug that has been widely used around the world for decades in cattle and small ruminants [3].

These treatments have been selected for use widely by Mexican farmers, sometimes in excessive or inadequate doses. The objective of this study was to evaluate these five treatments to control intestinal parasites in sheep in Ayapango, State of Mexico.

\section{Materials and Methods}

Ethical approval

The experiment was approved by Institutional Animal Ethics Committee.

\section{Selection of animals}

For this study, 107 Rambouillet breed sheep from the Ayapango, State of Mexico, were randomly selected in the autumn-winter. Specifically, this included 105 females and two males, with an age mean of 21.7 months. The flock was sent out daily for grazing, not separated by fences. Sheep were identified by ear tags, and all sheep had gone more than 8 months without deworming.

\section{Treatments}

Sheep were organized into five groups.

\section{Group 1}

Consisting of 18 female sheep dewormed with ivermectin $1 \%$ clorsulon $10 \%$ at a dosage of $2.0 \mathrm{mg} / \mathrm{kg}$ body weight, administered subcutaneously.

\section{Group 2}

Consisting of 21 female and one male sheep dewormed with $12 \%$ levamisole at a dosage of $6.0 \mathrm{mg} / \mathrm{kg}$, administered via deep intramuscular injection.

\section{Group 3}

Consisting of 26 females and one male sheep dewormed with $5 \%$ closantel sodium at a dosage of $15 \mathrm{mg} / \mathrm{kg}$, administered orally.

\section{Group 4}

Consisting of 18 female sheep dewormed with ivermectin $1 \%$ at a dosage of $4.0 \mathrm{mg} / \mathrm{kg}$, administered subcutaneously.

\section{Group 5}

Consisting of 22 female sheep dewormed with closantel $5 \% /$ albendazole $3.75 \%$ at a dosage of $10 \mathrm{mg} / \mathrm{kg}$, administered orally.
The use of a control group was not considered because the five treatments were evaluated and compared according to the difference in the number of eggs pre- and post-treatment.

After application of the treatments, sheep were placed in the same corral, and always had the same diet by grazing together in the same place.

\section{Analysis of fecal samples}

From these individuals, we took fecal samples directly from the rectum, which were identified and stored in plastic bags for later analysis. Sample processing was performed in the laboratory of parasitology and microbiology of the Amecameca University Center of the Autonomous University of the State of Mexico, 15 days after the drugs were administered, fecal samples were taken and analyzed by a coproparasitoscopically using the Faust flotation technique with $2.04 \mathrm{~g} / \mathrm{mol}$ zinc sulfate. McMaster chambers were used for subsequent egg counting and the determination of parasite load [10-12].

\section{Statistical analysis}

The results were analyzed using a KruskalWallis non-parametric test because the groups did not have the same number of animals, and the data did not present a normal distribution.

\section{Results and Discussion}

Table-1 shows that there was a statistically significant difference $(\mathrm{p}<0.0001)$ between number of eggs of Toxocara spp. before and after administration of $2.0 \mathrm{mg} / \mathrm{kg}$ ivermectin/clorsulon. In the case of Haemonchus spp., there was also a significant difference $(p=0.0279)$ between the number of eggs before and after the same treatment. The same was observed for Ostertagia spp. $(\mathrm{p}<0.0001)$ and Chabertia spp. $(p=0.0036)$. In contrast, there was no difference in the number of eggs of Moniezia spp. $(p=0.1271)$ before and after treatment.

In the comparison shown in Table-2, the number of Ostertagia spp. eggs before and after treatment showed a statistically significant difference $(p<0.0001)$. There was a significant difference in the number of eggs of Chabertia spp. $(\mathrm{p}<0.0001)$ after the administration of $6.0 \mathrm{mg} / \mathrm{kg}$ of levamisole, while for Toxocara spp. there was no significant difference in the number of eggs pre and post-treatment $(\mathrm{p}=0.087)$. This was also true for Haemonchus spp. $(\mathrm{p}=0.141)$ and Moniezia spp. $(\mathrm{p}=0.084)$.

Table-1: Mean number of eggs pre- and post-treatment with ivermectin/clorsulon in Group 1.

\begin{tabular}{lccccc}
\hline Parasite (eggs) & $\mathbf{n}$ & $\begin{array}{c}\text { Number of eggs* } \\
\text { pre-treatment }\end{array}$ & $\begin{array}{c}\text { Number of eggs* 15 days } \\
\text { post-treatment }\end{array}$ & $\boldsymbol{\chi}^{\mathbf{2}}$ & $\mathbf{p}^{* *}$ \\
\hline Toxocara spp. & 18 & 25.277 & 11.722 & 18.043 & $<0.0001$ \\
Haemonchus spp. & 18 & 21.166 & 15.833 & 4.832 & 0.0279 \\
Moniezia spp. & 18 & 20.111 & 16.888 & 2.327 & 0.1271 \\
Ostertagia spp. & 18 & 25.305 & 11.694 & 17.676 & $<0.0001$ \\
Chabertia spp. & 18 & 22.777 & 14.222 & 8.450 & 0.0036 \\
\hline
\end{tabular}

*Mean number of eggs, $* * p \leq 0.05$

Veterinary World, EISSN: 2231-0916 
Table- 3 shows that treatment with $15 \mathrm{mg} / \mathrm{kg}$ closantel sodium resulted in a statistically significant difference in the number of eggs of Toxocara spp. $(\mathrm{p}<0.0001)$, Ostertagia spp. $(\mathrm{p}<0.0001)$, and Chabertia spp. $(\mathrm{p}<0.0001)$, while no statistically significant difference was observed for Haemonchus spp. $(\mathrm{p}=0.060)$ or Moniezia spp. $(\mathrm{p}=0.1663)$.

Table-4 shows there was a statistically significant difference in the number of Toxocara spp. $(\mathrm{p}=0.0039)$, Haemonchus spp. $(\mathrm{p}=0.0019)$, and Ostertagia spp. $(\mathrm{p}=0.004)$ eggs after the administration of $4.0 \mathrm{mg} / \mathrm{kg}$ ivermectin, but for Moniezia spp. $(\mathrm{p}=0.0927)$ and Chabertia spp. $(\mathrm{p}=0.491)$, there was no significant difference in egg number.

In the group treated with $10 \mathrm{mg} / \mathrm{kg}$ closantel/albendazole (Table-5), there was a statistically significant difference in the Toxocara spp. egg number ( $\mathrm{p}=0.0007)$, in contrast to Cooperia spp. $(\mathrm{p}=0.129)$, Trichostrongylus spp. $(\mathrm{p}=0.177)$, Oesophagostomum spp. $\quad(p=0.664), \quad$ Haemonchus spp. $\quad(p=0.263)$, Trichuris spp. $(\mathrm{p}=0.408)$, Moniezia spp. $(\mathrm{p}=0.767)$, and Strongyloides spp. $(\mathrm{p}=0.416)$, which showed no differences in egg numbers after treatment.

The closurlon is use for treatment of flukes without effect in nematodes, although this drug combination is used for the treatment of flukes and nematodes, the coproparasitoscopic tests on samples from sheep treated with ivermectin/clorsulon demonstrated efficiency in removing most parasites, especially Haemonchus spp., one of the most commonly implicated parasites in weight loss in sheep [13]. The administration of these two drugs had a positive effect

Table-2: Comparison of the number of eggs pre- and post-treatment with levamisole in Group 2.

\begin{tabular}{lccccc}
\hline Parasite (eggs) & $\mathbf{n}$ & $\begin{array}{c}\text { Number of eggs* } \\
\text { pre-treatment }\end{array}$ & $\begin{array}{c}\text { Number of eggs* 15 days } \\
\text { post-treatment }\end{array}$ & $\boldsymbol{\chi}^{\mathbf{2}}$ & $\mathbf{p}^{* *}$ \\
\hline Toxocara spp. & 22 & 24.727 & 20.272 & 2.928 & 0.087 \\
Haemonchus spp. & 22 & 24.068 & 20.931 & 2.161 & 0.141 \\
Moniezia spp. & 22 & 24.954 & 20.045 & 2.983 & 0.084 \\
Ostertagia spp. & 22 & 31.250 & 13.750 & 21.856 & $<0.0001$ \\
Chabertia spp. & 22 & 31.772 & 13.227 & 25.820 & $<0.0001$ \\
\hline
\end{tabular}

*Mean number eggs, $* * \mathrm{p} \leq 0.05$

Table-3: Comparison of the number of eggs pre- and post-treatment with closantel sodium in Group 3.

\begin{tabular}{lccccc}
\hline Parasite (eggs) & $\mathbf{n}$ & $\begin{array}{c}\text { Number of eggs* } \\
\text { pre-treatment }\end{array}$ & $\begin{array}{c}\text { Number of eggs* 15 days } \\
\text { post-treatment }\end{array}$ & $\boldsymbol{\chi}^{\mathbf{2}}$ & p** \\
\hline Toxocara spp. & 27 & 35.555 & 20.444 & 16.022 & $<0.0001$ \\
Haemonchus spp. & 27 & 30.518 & 24.481 & 3.537 & 0.060 \\
Moniezia spp. & 27 & 29.722 & 25.277 & 1.916 & 0.1663 \\
Ostertagia spp. & 27 & 40.314 & 14.685 & 37.314 & $<0.0001$ \\
Chabertia spp. & 27 & 37.611 & 17.388 & 24.502 & $<0.0001$ \\
\hline
\end{tabular}

*Mean number of eggs, $* * p \leq 0.05$

Table-4: Comparison of the number of eggs pre- and post-treatment with ivermectin in Group 4.

\begin{tabular}{|c|c|c|c|c|c|}
\hline Parasite (eggs) & $\mathbf{n}$ & $\begin{array}{c}\text { Number of eggs* } \\
\text { pre-treatment }\end{array}$ & $\begin{array}{c}\text { Number of eggs* } 15 \text { days } \\
\text { post-treatment }\end{array}$ & $\chi^{2}$ & p** \\
\hline Toxocara spp. & 18 & 22.0 & 15.0 & 8.352 & 0.0039 \\
\hline Haemonchus spp. & 18 & 23.527 & 13.472 & 9.628 & 0.0019 \\
\hline Moniezia spp. & 18 & 20.416 & 16.583 & 2.827 & 0.0927 \\
\hline Ostertagia spp. & 18 & 23.222 & 13.777 & 8.127 & 0.004 \\
\hline Chabertia spp. & 18 & 19.333 & 17.666 & 0.472 & 0.491 \\
\hline
\end{tabular}

*Mean number of eggs, $* * \mathrm{p} \leq 0.05$

Table-5: Comparison of the number of eggs pre- and post-treatment with closantel/albendazole in Group 5.

\begin{tabular}{lccccc}
\hline Parasite (eggs) & $\mathbf{n}$ & $\begin{array}{c}\text { Number of eggs* } \\
\text { pre-treatment }\end{array}$ & $\begin{array}{c}\text { Number of eggs* 15 days } \\
\text { post-treatment }\end{array}$ & $\boldsymbol{\chi}^{\mathbf{2}}$ & $\mathbf{p}^{* *}$ \\
\hline Toxocara spp. & 22 & 26.714 & 17.500 & 11.441 & 0.0007 \\
Cooperia spp. & 22 & 24.857 & 19.272 & 2.295 & 0.129 \\
Trichostrongylus spp. & 22 & 24.523 & 19.590 & 1.817 & 0.177 \\
Oesophagostomum spp. & 22 & 22.761 & 21.272 & 0.188 & 0.664 \\
Haemonchus spp. & 22 & 24.095 & 20.000 & 1.251 & 0.263 \\
Trichuris spp. & 22 & 23.523 & 20.545 & 0.684 & 0.408 \\
Moniezia spp. & 22 & 22.428 & 21.590 & 0.087 & 0.767 \\
Strongyloides spp. & 22 & 23.404 & 20.659 & 0.659 & 0.416 \\
\hline
\end{tabular}

*Mean number of eggs, $* * \mathrm{p} \leq 0.05$

Veterinary World, EISSN: 2231-0916 
on sheep by reducing the number of various intestinal parasites [14]. In a study in rats infected with Fasciola, by Sibille et al., they found that the combination of these anthelmintics in male mice had little efficacy unlike females where efficacy was higher, but in general, if there were flukes reduction post-treatment [15].

Sakhawat et al., in 1997, they reported that levamisole had $100 \%$ efficiency that no nematode eggs were recovered from animals treated [16]. In more recent studies have shown that levamisole administration in sheep does not reduce the majority of intestinal parasites [17]. Haemonchus spp. has developed resistance due to the regular use of this anthelmintic in sheep [18], this is consistent with our results because the number of eggs of Toxocara spp., Haemonchus spp., and Moniezia spp. not decreased, with this treatment, although the number of eggs to Ostertagia spp. and Chabertia spp. decreased significantly, which means that, the parasites aforementioned (Toxocara spp., Haemonchus spp. and Moniezia spp.) they were resistant to this drug.

Closantel sodium has efficacy against strongyle populations which are resistant to ivermectin [19], Similarly, the results to this study, as can be seen in Table-3 where we see that; Toxocara spp., Ostertagia spp., Chabertia spp., if they decrease significantly, but it is not very useful against Haemonchus spp. as describe Jabbar et al., in 2013 [20].

In this research ivermectin shows excellent nematicide efficacy, which is consistent with that reported con Muñoz et al., but also it mentions that, this has diminished over time, especially in the genera Trichostrongylus and Haemonchus spp., which have developed resistance [21]. This can happen for various reasons, including the application of inadequate doses of ivermectin, the absence of a timetable for deworming according to the cycles of the parasites and their seasonality, as well as the introduction of animals from areas where resistance has occurred [22].

In our results find that a combination of closantel/albendazole, it was only effective against Toxocara spp. and it had no effect on Cooperia spp., Trichostrongylus spp., Oesophagostomum spp., Haemonchus spp., Trichuris spp., Moniezia spp. and Strongyloides spp. in our study, which coincides with that reported by other authors who mention that; closantel has demonstrated ineffectiveness in deworming programs, which is why it is suggested to alternate it with other anthelmintics to improve its effect [23]. Meanwhile, albendazole has a prolonged effect and it is most effective when treatment is administered for an extended period [24]. Thus, even in combination, these two anthelmintics are not a good alternative for deworming.

\section{Conclusion}

Misuse and uncontrolled anthelmintic administration in sheep production systems have led to the development of resistance in some parasites. Therefore, it is important to monitor this problem and parasite infestation triggers nutritional, health, and economic problems for producers. The results of this study show that effective control of intestinal parasites in sheep can be achieved using a combination ivermectin and clorsulon, which reduces the incidence of intestinal parasitosis.

\section{Authors' Contributions}

$\mathrm{CR}$ and EA planned and designed the study. EA collected samples. EA analyzed samples. LG, RH, and GM analyzed the data and provided technical support. EA and $\mathrm{RH}$ prepared the manuscript with guidance from the other authors. All authors read and approved the final manuscript.

\section{Acknowledgments}

The authors thank the Parasitology Laboratory of Veterinary Clinic Pet "CLIVAC" of the University Center UAEM Amecameca, Mexico State, Mexico, to give the necessary facilities for the accomplishment of this research. To CONACyT and Doctorate in Agricultural Sciences and Natural Resources of Autonomous University of Mexico State by the grant of scholarship for postgraduate studies.

\section{Competing I nterests}

The authors declare that they have no competing interests.

\section{References}

1. González, G.R., Córdova, P.C., Torres, H.G. and Mendoza, G.P. (2011) Prevalence of gastrointestinal parasites in sheep slaughtered in a trail of Tabasco, Mexico. Vet. Mex., 42: 125-127.

2. Rojas, H.S., Gutiérrez, S.I., Olivares, P.J. and Valencia, A.M.T. (2007) Prevalence of gastrointestinal nematodes in sheep grazing on the top of the MPIO. Cuetzala del Progreso, Guerrero-Mexico. Rev. Electrón. Vet., 8: 1695-7504.

3. Kabaka, W.M., Kitala, P.M., Gitau, G.K., Maingi, N. and Van Leeuwen, J.A. (2012) The efficacy of albendazole and moxidectin in the control of nematode infection in dairy cattle. Bull. Anim. Health Prod. Afr., 60: 393-397.

4. Barrios, M., Sandoval, E., Carrillo, H., Dominguez, L. and Marquez, O. (2010) Evaluation of the effect of two forms of oral administration of fenbendazole on the elimination of gastrointestinal nematodes eggs and weight gain in calves double purpose. Rev. Electrón. Vet., 11: 1695-7504.

5. Moore, D.A., Terrill, T.H., Kouakou, B., Shaik, S.A., Mosjidis, J.A., Miller, J.E., Vanguru, M., Kannan, G. and Burke, J.M. (2008) The effects of feeding Sericea lespedeza hay on growth rate of goats naturally infected with gastrointestinal nematodes. J. Anim. Sci., 86: 2328-2337.

6. Montalvo, A.X., López, A.M.E., Vázquez, P.V., Liébano, H.E. and Mendoza, G.P. (2006) Anthelmintic resistance of gastrointestinal nematodes in sheep to fenbendazole and ivermectin in the northwest region of the state of Tlaxcala. Téc. Ресu. Мex., 44: 81-90.

7. Solis, R.C., Wilcock, A., Arellano, C.S., Morales, L.A. and McEwen, A.S. (2011) Residues in cattle slaughtered in federally inspected abattoirs in Nuevo Leon, Mexico. Food Prot. Trends, 31: 212-215.

8. Cruz, R.M., Martínez, M.I., López-Collado, J., 
Vargas-Mendoza, M., González-Hernández, H. and Fajersson, P. (2012) Effect of ivermectin on the survival and fecundity of Euoniticellus intermedius (Coleoptera: Scarabaeidae). Rev. Biol. Trop., 60: 333-345.

9. González-Garduño, R., López-Arellano, M.E., OjedaRobertos, N.E., Liébano-Hernández, E. and Mendoza-de Gives, P. (2014) In vitro and field diagnosis of anthelmintic resistance in gastrointestinal nematodes of small ruminants. Arch. Med. Vet., 46: 399-405.

10. Pajuelo, C.G., Luján, R.D., Paredes, P.B. and Tello, C.R. (2006) Application of the technique of spontaneous tube sedimentation diagnostic hookworms. Rev. Biomed., 17: 96-101.

11. Sánchez, M.R.M., Gómez, N.M. and Alva, E.S.I. (2000) Program quality assessment among laboratories. XXVI. The diversity of coproparasitoscopic techniques and quality. Lab. Acta, 12: 139-143.

12. Sandoval, E., Morales, G., Ybarra, N., Barrios, M. and Borges, J. (2011) Comparison between two different models of McMaster cameras used for stool samples counting in the diagnosis of infections by gastrointestinal nematodes in ruminants. Zootec. Trop., 4: 495-501.

13. Mireles, M.E.J., Valencia, A.M.T. and Gutiérrez, S.I. (2009) Natural gastrointestinal parasitosis and daily weight gain of infants lambs in the dry tropic of Guerrero, Mexico. Rev. Electrón. Vet., 11: 1695-7504.

14. Martínez, M.I., Cruz, R.M. and Pierre, L.J. (2000) Effect of different pasture management and livestock on dung beetles Ataenius apicalishinton and Ataenius sculptor Harold (Scarabaeidae: Aphodiinae: Eupariini). Acta Zool. Mex., 80: 185-196.

15. Sibille, P., Calleja, C., Carreras, F., Bigot, K., Galtier, P. and Boulard, C. (2000) Fasciola hepatica: Influence of gender and liver biotransformations on flukicide treatment efficacy of rats infested and cured with either clorsulon/ivermectin or triclabendazole. Exp. Parasitol., 94: 227-237.

16. Sakhawat, A., Anwar, A.H.B., Hayat, Z.I. and Hayat, S. (1997) Field evaluation of anthelmintic efficacy of levamisole, albendazole, ivermectin and morantel tartrate against gastrointestinal nematodes of sheep. Pak. Vet., 17: 114-116.

17. Rimbaud, E., Zúñiga, P., Doña, M., Pineda, N., Luna, L., Rivera, G., Molina, L., Gutiérrez, J. and Venegas, J. (2005) First diagnosis of resistance to macrocyclic lactones levamisole and gastrointestinal parasitic nematodes in sheep in Nicaragua. Rev. Electrón. Vet., 6: 1695-7504.

18. Torres, A.J.F., Villarroel, A.M.S., Rodríguez, A.F., Gutiérrez, S.I. and Alonso, D.M.A. (2003) Diagnosis of gastrointestinal nematodes resistant to benzimidazoles and imidazothiazoles in a goat herd Yucatan, Mexico. Rev. Biomed., 14: 75-81.

19. Arece, J., Rodríguez, D.J.G. and Olivares, J.L. (2008) Closantil effectiveness of $5 \%$ ( against gastrointestinal strongyles of sheep. Rev. Salud Anim., 30: 59-62.

20. Jabbar, A., Campbell, J.D.A., Charles, A.J. and Gasser, B.R. (2013) First report of anthelmintic resistance in Haemonchus contortus in alpacas in Australia. Parasit. Vectors, 6: 243.

21. Muñoz, A.J., Angulo, C.F., Ramírez, R., Vale, O.O., Chacín, E., Simoes, D. and Atencio, A. (2008) Anthelmintic efficacy of doramectin $1 \%$ ivermectin $1 \%$ and ricobendazol $15 \%$ against gastrointestinal nematodes of hair sheep. Rev. Cient. FCV-LUZ., 18: 12-16.

22. Mamani, L.L.W. and Cayo, R.F. (2009) Determination of anthelmintic resistance (Moniezia expansa, Moniezia benedeni and Thysanosoma actioides) against albendazole and fenbendazole in sheep in three herds of La Paz-Bolivia. Rev. Electrón. Vet.,10: 1695-7504.

23. Vilmaris, M., Rodríguez, D.J.G., Alfonso, P., Martín, J., Mengana, E., Pérez, E., Moya, S. and Matos, K. (2011) antiparasitic efficacy of ivermectin and closantel against Oestrus ovis in naturally infected sheep. Rev. Salud Anim., 3: 184-189.

24. Torrelio, A., Vino, L., Mamani, L.W. and Loza, M.M. (2011) Determination of the antihelmintic efficacy of albendazole and fenbendazole in Moniezia expanza (Rudolphi 1810) and Thysanosoma actinioides (Diesing 1834) (Cestoda: Anoplocephalidae) in creole sheep infected naturally in a stay of the community of Comanche, county Pacajes department of the la Paz, Bolivia. J. Selva Andina Res. Soc., 2: 2-16.

$* * * * * * * *$ 